\title{
Effects of continuous exercise training at aerobic threshold on ventilation inefficiency in chronic heart failure
}

\author{
Stefano Scarpa* \\ University of Padua and Telematic University Giustino Fortunato of Benevento, Italy
}

\begin{abstract}
Chronic Heart Failure (CHF) is a complex syndrome characterised by ventilation inefficiency, as indicated by the increasing of the minute ventilation-carbon dioxide production slope $\left(\mathrm{VE} / \mathrm{VCO}_{2}\right)$. In the present work we investigated the effects of a "low impact" continuative aerobic training on a powerful prognostic indicator as the $\mathrm{VE} / \mathrm{VCO}_{2}$ slope in $\mathrm{CHF}$.

Background: Chronic Heart Failure (CHF) is a complex syndrome characterised by ventilation inefficiency, as indicated by the increasing of the minute ventilationcarbon dioxide production slope (the $\mathrm{VE} / \mathrm{VCO}_{2}$ slope), and it is correlated with two predominant symptoms: dyspnea and reduced aerobic performance.

We investigated how ventilatory efficiency improves (decreasing in the VE/VCO 2 slope) after a period of "low impact" supervised continuative aerobic training (SAT) and after a subsequent period of non supervised continuative aerobic "home" training (NST) in CHF patients.

Methods: Individuals with CHF ( $=22$ ) were trained (40 minutes of cycling at the aerobic threshold, 3 times/week) for 8 weeks and continued a non-monitored training for another 8 weeks.

Results: After SAT there was an increasing of peak exercise $\mathrm{O}_{2}$ uptake ( $\left.\mathrm{pVO},+7.8 \%\right)$, exercise testing duration (+14.5\%), work rate $(\mathrm{Watts})$ corresponding respectively to 2 and $3 \mathrm{mmol} / 1$ of blood lactate (respectively $+20.2 \%$ and $+18.4 \%)$. After overall training there was a decreasing of the $\mathrm{VE} / \mathrm{VCO}$ slope $(-6.5 \%)$ and ventilation measured at the maximum work rate in the baseline exercise testing (relative maximal ventilation, $-21 \%$ ).

Conclusions: Low impact training may improve aerobic performance and functional ability. The training increases the $\mathrm{pVO}_{2}$ values and has a positive effect on the powerful prognostic indicator, the $\mathrm{VE} / \mathrm{VCO}_{2}$ slope. Finally it has a lot of benefits and helps to guarantee the possibility for an active physical regimen in $\mathrm{CHF}$ population in order to maintain all positive effects that exercise produces.
\end{abstract}

\section{Introduction}

Ventilatory efficiency is commonly assessed by the minute ventilation-carbon dioxide production slope $\left(\mathrm{VE}-\mathrm{VCO}_{2}\right)$ [1-3]. Chronic Heart Failure (CHF) is a complex syndrome characterised by ventilation inefficiency, as indicated by the increased $\mathrm{VE} / \mathrm{VCO}_{2}$ slope, correlated with two predominant symptoms: dyspnea and reduced aerobic performance $[3,4]$. The $\mathrm{VE} / \mathrm{VCO}_{2}$ slope is considered as a powerful prognostic indicator in heart failure population [1,5-11]. Risk of mortality is thought to increased when $\mathrm{VE} / \mathrm{VCO}_{2}$ slope values are greater than 45 when it is calculated as the last value of three during the last 30 seconds of exercise [12] or greater than 34 when it is measured over all the curve $[7,11,13]$ or greater than 32.6 when it is measured excluding ventilatory compensation due to metabolic acidosis [2].

The increased $\mathrm{VE} / \mathrm{VCO}_{2}$ slope in $\mathrm{CHF}$ could be explained by the following mechanisms: a large dead space and high values of physiological dead space-tidal volume ratio [2]; low values of the arterial $\mathrm{CO}_{2}$ partial pressure [2]; a ventilation-perfusion mismatch [14-16]; a impaired metabolic gas diffusion [14]; abnormalities in endothelial and working muscle function [2]; changes in respiratory musculature with a need of excessive ventilatory effort $[2,17,18]$; an impaired central and peripheral control of ventilation [2,19-21].

A study of Guazzi, et al. (2004) showed that a regular aerobic exercise training (intensity at $60-80 \%$ according to heart rate reserve method) contributes to improve ventilatory efficiency and exercise performance in CHF. A similar exercise program seemed to increase lung diffusion, alveolar-capillary conductance, pulmonary capillary blood volume, peak exercise $\mathrm{O}_{2}$ uptake $\left(\mathrm{pVO}_{2}\right), \mathrm{VO}_{2}$ at anaerobic threshold and decrease the $\mathrm{VE} / \mathrm{VCO}_{2}$ slope [3].

The aim of the present study is to determine the improvement in ventilation efficiency (decreasing in the $\mathrm{VE} / \mathrm{VCO}_{2}$ slope) and exercise performance after a period of "low impact" supervised aerobic training (SAT) -intensity correspondent to aerobic threshold, approximately $60 \%$ of $\mathrm{pVO}_{2}$ - and after a subsequent period of non supervised "home" training (NST) in CHF population.

\section{Material and methods}

\section{Study subjects}

Twenty-two patients ( 16 male and 6 female, aged $61.40 \pm 7.5$ ) with symptomatic CHF in a stable condition were enrolled in this study. CHF was due to either ischaemic (14 patients) or idiopathic dilated cardiomyopathy ( 8 patients). The criteria for their eligibility were: medically stable heart failure in NYHA class II-III for at least 3 months

Correspondence to: Stefano Scarpa, University of Padua and Telematic University Giustino Fortunato of Benevento, Italy, E-mail: stefano.scarpa@unipd.it

Key words: Heart failure, Continuative aerobic training, Ventilation inefficiency

Received: March 13, 2018; Accepted: March 26, 2018; Published: March 29, 2018 
before the study, left ventricular dysfunction with Ejection Fraction $\leq$ $40 \%$, and $\mathrm{pVO}_{2} \leq 25 \mathrm{ml} / \mathrm{kg} / \mathrm{min}$. Exclusion criteria were: myocardial infarction or unstable angina within the previous 6 months, aortic stenosis, uncontrolled hypertension, exercise-limiting peripheral artery disease, de-compensated diabetes mellitus, orthopedic limitations or any other clinical condition precluding regular participation in exercise sessions. Patients received standard medical treatment, and medications remained unaltered throughout the study.

Written informed consent was obtained from each patient under the supervision of the Local Ethics Committee, and the investigation conformed to the principles outlined in the Declaration of Helsinki.

\section{Study design}

The study was conducted prospectively, without any blinding procedure, and each patient acted as her/his own control. All patients received a complete evaluation at the beginning of the study, after 8 weeks of continuous SAT and again after 8 weeks of the subsequent phase (continuous NST). Each evaluation included two symptomlimited bicycle exercise tests (one with gas exchange analysis, one with capillary blood sample collection for lactate analysis), medical examinations and skinfolds.

The outcome measures for this study were the $\mathrm{VE} / \mathrm{VCO}_{2}$ slope, $\mathrm{pVO}_{2}(\mathrm{ml} / \mathrm{kg} / \mathrm{min}$ ), relative maximal ventilation (ventilation measured at the maximum work rate obtained in the baseline exercise testing), absolute maximal ventilation (ventilation measured at the maximum work rate obtained in each exercise testing), dead space-tidal volume ratio, duration of exercise (min:sec), work rate (Watts), aerobic and anaerobic thresholds (watts and heart rate values corresponding to respectively $2 \mathrm{mmol} / \mathrm{l}$ and $4 \mathrm{mmol} / \mathrm{l}$ of blood lactate concentration), and anthropometric measurements (height, body weight, body mass index, 9 skinfolds and 7 body circumferences).

\section{Exercise tests}

\section{Cardiopulmonary exercise test}

An incremental upright cardiopulmonary exercise test was performed on an electronically braked cycle ergometer (Meditronic M700, Karlsruhe, Germany). To stabilize gas measurements, patients were asked to remain still on the ergometer for 3 minutes before exercising. After a 3 minute warm up at a 15 Watts workload, a ramp protocol of $10 \mathrm{Watt} / \mathrm{min}$ was started and continued until exhaustion at a constant pedaling rate of $60 \mathrm{rpm}$. A 12-lead electrocardiogram was monitored throughout the test (Marquette MAC8, Jupiter Florida) and blood pressure was measured manually by a cuff sphygmomanometer every minute. Respiratory gas exchange measurements were obtained breath-by-breath using a computerized metabolic chart (Vmax Sensor Medics, Yorba Linda, California). Calibrations of volumes and gases $\left(\mathrm{O}_{2}\right.$ and $\left.\mathrm{CO}_{2}\right)$ were performed before each test. The mean oxygen uptake over the last 20 seconds of exercise was $\mathrm{pVO}_{2}$.

\section{Measurements of the VE/ $\mathrm{VCO}_{2}$ slope}

Cardiopulmonary exercise testing also permitted the determination of the $\mathrm{VE} / \mathrm{VCO}_{2}$ slope, relative maximum ventilation, absolute maximum ventilation and dead space-tidal volume ratio. The VE/ $\mathrm{VCO}_{2}$ slope was measured by linear regression, excluding the non linear part of the data after the onset of ventilatory compensation for metabolic acidosis [2,3,22].

\section{Calculation of aerobic threshold and target heart rate}

Two days after the cardiopulmonary test, patients performed a second symptom-limited exercise test on the same cycle ergometer, starting at a 15 Watts workload for 3 minutes followed by a 20 Watt increase every 3 minutes until exhaustion. At the end of each 3-minute step, a $20 \mu \mathrm{L}$ capillary blood sample was taken from the ear-lobe for lactate determination using the enzymatic-amperometric measuring principle (Super GL Dr Muller Geratebau, Freital, Germany). The target training heart rate for each patient was determined from the relationship between lactate concentration and heart rate. The target heart rate was identified at $2 \mathrm{mmol} / \mathrm{L}$ of lactate which, in our patients, corresponded to approximately $60 \%$ of $\mathrm{pVO}_{2}$ and to $90 \%$ of anaerobic threshold previously measured by the V-slope method [23]. This 2 $\mathrm{mmol} / \mathrm{L}$ of lactate workload, determined from the lactate-workload plot, was named aerobic threshold.

\section{Training protocol}

Patients exercised on an upright bicycle ergometer 3 times a week for 8 weeks. Each session lasted 55 minutes, beginning with a 5 -minute warm up at 15 Watts followed by 45 minutes of cycling at the target heart rate and finished with a 5-minute cool-down at 15 Watts. A capillary blood sample was taken from all patients at least twice during each exercise session to ensure that the target training intensity corresponding to $2-2.5 \mathrm{mmol} / \mathrm{L}$ of lactate was achieved and maintained. In the event of a lower or a higher lactate concentration, the workload was immediately adjusted [24]. All sessions were held at the hospital gymnasium under the supervision of an expert sport scientist.

\section{Statistical analyses}

All data were processed using the SPSS 21.0 program. Age and anthropometric characteristics are expressed as mean value \pm standard deviation. Comparisons between groups were analyzed by unpaired t test (2-sided) or Analysis of variance (one-way ANOVA) for comparisons with $>2$ subgroups. Bonferroni post-hoc multiple comparisons were performed when appropriate. The alpha-error probability was set at $\mathrm{p}<0.05$ (2-sided).

\section{Results}

All 22 patients recruited for the study finished the 8 weeks of SAT without any cardiovascular or muscle-skeletal complication. At the baseline assessment they showed the following anthropometric characteristics: weight $83.31 \pm 16.3 \mathrm{~kg}$, height $170.1 \pm 8.51 \mathrm{~cm}$, BMI 28.67 $\pm 4.07 \mathrm{~kg} / \mathrm{m}^{2}$, muscle mass $40.12 \pm 3.02 \%$ and fat mass $25.13 \pm 5.67 \%$. There were no significant modifications after the 8 weeks of SAT, while there was a significant increasing of both muscle mass and fat mass after 8 more weeks of NST (Table 1).

For what concerns Cardiopulmonary exercise testing $\mathrm{pVO}_{2}$ changed from a baseline average value of $15.79 \pm 3.78 \mathrm{ml} / \mathrm{kg} / \mathrm{min}$ to $17.03 \pm 4.06$ $\mathrm{ml} / \mathrm{kg} / \mathrm{min}(+7.8 \%, \mathrm{p}<0.001)$ after 8 weeks of SAT and it decreased again to baseline values after 8 more weeks of NST (Table 2). The VE/ $\mathrm{VCO}_{2}$ slope showed a non significant decreasing after 8 weeks of SAT, but it significantly decreased after the 16 weeks of overall training. The baseline average value was $31.91 \pm 6.2$. The average value after 8 weeks was $30.86 \pm 4.61$ and $29.84 \pm 4.49(-6.5 \%, \mathrm{p}<0.05)$ after 16 weeks (Table 3). The relative maximal ventilation showed a trend similar to the VE/ $\mathrm{VCO}_{2}$ slope ( $-21 \%$ after 16 weeks of overall training, $\left.\mathrm{p}<0.0005\right)$, while the absolute maximal ventilation did not show any significant variation. The dead space-tidal volume ratio showed a non significant decreasing trend.

Results originating from Modified Mader testing showed a significant increasing of the work rate (Watts) expressed at 2 and 3 lactate $\mathrm{mmol} / \mathrm{l}$ after 8 weeks of SAT in comparison with baseline values $(\mathrm{p}<0.005)$. The elevated values returned to the baseline values after a further NST (Table 4). 
Table 1. Anthropometric features.

\begin{tabular}{|c|c|c|}
\hline & BASELINE & 8 WEEKS \\
\hline Age & $61.40 \pm 7.5$ & $61.40 \pm 7.5$ \\
\hline Weight (kg) & $83.31 \pm 16.30$ & $83.27 \pm 15.87$ \\
\hline Height (cm) & $170.07 \pm 8.51$ & $170.07 \pm 8.51$ \\
\hline BMI (kg/m $)$ & $28.67 \pm 4.07$ & $29.89 \pm 5.47$ \\
\hline Muscle Mass (\%) & $40.12 \pm 3.02$ & $40.57 \pm 2.96$ \\
\hline Fat Mass (\%) & $25.13 \pm 5.67$ & $25.47 \pm 5.85$ \\
\hline $\begin{array}{l}\text { Anthropometric features at baseline, after 8 weeks of SAT (supervised aerobic training) and after further 8 weeks of NST (non-supervised training). } \\
\text { All values are expressed as means } \pm \text { standard deviations. } \\
\text { Significant differences are denoted with the symbol “*” (p }<0.05) .\end{array}$ \\
\hline
\end{tabular}

Table 2. Maximal values of variables measured during cardiopulmonary exercise testing.

\begin{tabular}{|c|c|c|c|}
\hline & BASELINE & 8 WEEKS & 16 WEEKS \\
\hline $\mathbf{p V O}_{2}(\mathrm{ml} / \mathrm{kg} / \mathrm{min})$ & $15.79 \pm 3.78$ & $17.03 \pm 4.06^{*}$ & $16.27 \pm 4.16$ \\
\hline Work Rate max (Watts) & $98.67 \pm 26.96$ & $110.67 \pm 26.58 * * *$ & $108 \pm 29.33 * *$ \\
\hline Heart Rate max (bpm) & $122 \pm 16.7$ & $123.7 \pm 19.4$ & $122.1 \pm 16.3$ \\
\hline Exercise duration (min) & $9.23 \pm 2.73$ & $10.57 \pm 2.95 * * *$ & $10.38 \pm 3.09^{* *}$ \\
\hline
\end{tabular}

Table 3. Ventilatory variables measured during cardiopulmonary exercise testing.

\begin{tabular}{|c|c|c|c|}
\hline & BASELINE & 8 WEEKS & 16 WEEKS \\
\hline $\mathrm{VE} / \mathrm{VCO}_{2}$ slope & $31.91 \pm 6.2$ & $30.86 \pm 4.61$ & $29.84 \pm 4.49^{*}$ \\
\hline Absolute maximal ventilation $(1 / \mathrm{min})$ & $51.19 \pm 13.12$ & $54.5 \pm 12.43$ & $52.46 \pm 15.25$ \\
\hline Relative maximal ventilation $(1 / \mathrm{min})$ & $51.19 \pm 13.12$ & $41.21 \pm 9.64 * *$ & $40.34 \pm 14.66^{* *}$ \\
\hline Peak dead space-tidal volume ratio & $0.24 \pm 0.07$ & $0.22 \pm 0.07$ & $0.21 \pm 0.06$ \\
\hline
\end{tabular}

Table 4. Modifications of aerobic and anaerobic threshold measured during modified mader testing.

\begin{tabular}{|c|c|c|c|}
\hline & BASELINE & 8 WEEKS & 16 WEEKS \\
\hline Watts $2 \mathrm{mmol} / \mathrm{L}$ & $63.2 \pm 20.98$ & $76 \pm 21.70^{*}$ & $65 \pm 19.85$ \\
\hline Watts $3 \mathrm{mmol} / \mathrm{L}$ & $80.6 \pm 22.74$ & $95.43 \pm 25.27^{*}$ & $88.38 \pm 18.13$ \\
\hline
\end{tabular}

\section{Discussion}

From the analysis of results we observed an increasing in both exercise performance and functional ability after SAT in CHF patients. After 8 weeks patients expressed a higher work rate level and a longer exercise time during Cardiopulmonary testing. At the same time patients also achieved a decreased lactate concentration for the same sub-maximal intensity during Modified Mader testing. Those modifications regressed after further 8 weeks period of NST.

First of all, we aimed to assess the effects of our "low impact" training protocol on the $\mathrm{VE} / \mathrm{VCO}_{2}$ slope. A previous study had shown that aerobic high intensity training contributed to the reduction of the $\mathrm{VE} / \mathrm{VCO}_{2}$ slope after a period of 8 weeks and that the slope regressed to the baseline values after 8 more weeks of strict de-training [3]. The findings of our exercise protocol contrasted in part with the findings of the other studies. In our study the $\mathrm{VE} / \mathrm{VCO}_{2}$ slope showed a non significant decrease after 8 weeks of SAT, and a significant decrease after 8 more weeks of NST (Figure 1). Probably, to see a significant improvement in 8 weeks on this parameter it is necessary to exercise a high intensity training. However, in other studies, it has been observed that there are not significant difference between an high-intensity interval training and a continuous aerobic exercise training in terms of peak heart rate, peak minute ventilation, $\mathrm{VE} / \mathrm{VCO}_{2}$ slope and respiratory exchange ratio, body mass, blood pressure, etc. [25].
The obtained results are also controversial because $\mathrm{pVO}_{2}$ improved after 8 weeks of SAT and seemed to regress at the baseline values after the second 8 week period while the $\mathrm{VE} / \mathrm{VCO}_{2}$ slope decreased significantly after 16 weeks of overall training showing a non significant decrease after the first 8 week period of SAT (Figure 2). A possible explanation might be that those two parameters depend on different mechanisms and it is possible that different training intensity versus duration slopes have different effects on those mechanisms.

Our protocol was characterised by a low impact approach $(\sim 60 \%$ of $\mathrm{pVO}_{2}$ ) during the first 8 weeks period. We also asked patients to continue a low intensity training program at home (NST) during the subsequent 8 weeks of SAT discontinuation. It is possible that in our study the $\mathrm{VE} / \mathrm{VCO}_{2}$ reduction (-6.5\% in 16 weeks) could be explained through a improvement of lung diffusion and of alveolar-capillary membrane diffusing capacity [3]. Reduction could also be explained by a reduction of interstitial pulmonary oedema [11]. We observed an increasing of both muscle and fat mass for the same body weight that could be explained by the decrease of body interstitial water. We also observed a non significant decreasing trend of peak dead space-tidal volume ratio that could be explained by a redistribution of the lung blood stream with reperfusion of the previously excluded alveolar. Finally, an important variable to explain the $\mathrm{VE} / \mathrm{VCO}_{2}$ slope decrease might be the relative decrease of the maximal ventilation after 16 weeks of overall training. 


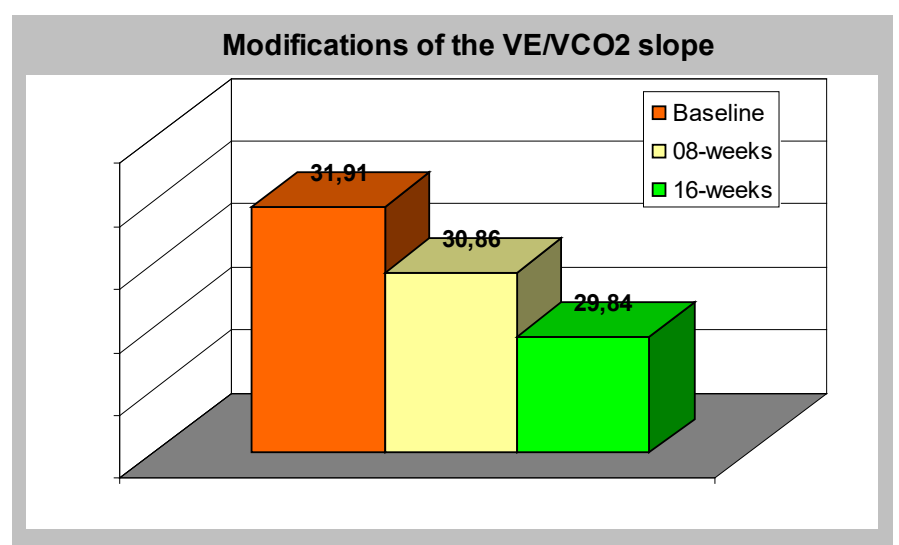

Figure 1. Modifications of the $\mathrm{VE} / \mathrm{VCO}_{2}$ slope values. $\mathrm{p}<0.05$ after 16 weeks.

Comparisons between peak VO2 and the VE/VCO2 slope

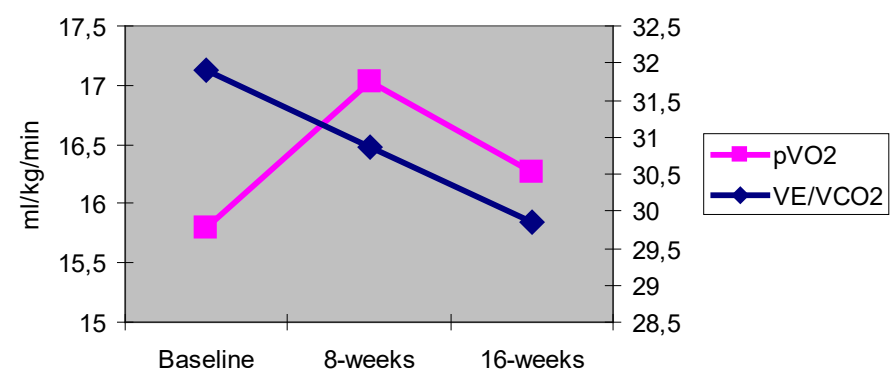

Figure 2. Comparisons between $\mathrm{pVO}_{2}$ and the $\mathrm{VE} / \mathrm{VCO}_{2}$ slope. $\mathrm{p}<0.001$ for $\mathrm{pVO}_{2}$ after 8 weeks and $\mathrm{p}<0.05$ for $\mathrm{VE} / \mathrm{VCO}_{2}$ after 16 weeks.

\section{Conclusions}

The CHF patients seemed to prefer a low intensity training. Physical and psychological symptoms, such as dyspnea and a reduced aerobic performance, created a particular "fear" towards physical activity, especially when it involved a high intensity. A "low impact" training has a lot of benefits: it reduces the onset risk of typical symptomatology, it is more safe, it reduces the number of drop-outs, it is more simple to perform and it could be easily continued at home or monitored by qualified staff at fitness centres. For the CHF patients it would be very important to continue an active physical regimen for the rest of their lives in order to maintain the benefits that exercise produces [26].

In the present study we showed that a low impact training (SAT) could improve aerobic performance, functional ability and the $\mathrm{pVO}_{2}$ values. A longer period of training (SAT+NST) seemed to have a positive effect on the powerful prognostic indicator, the $\mathrm{VE} / \mathrm{VCO}_{2}$ slope.

Further investigations could lead to a better understanding of the role that different methods of training have on the $\mathrm{VE} / \mathrm{VCO}_{2}$ in $\mathrm{CHF}$. To achieve an improvement of the $\mathrm{VE} / \mathrm{VCO}_{2}$ using a low impact approach, one probably needs a longer period of training. New studies might clarify how training intensity versus duration slope influences or modifies this prognostic indicator in the CHF population. Though monitored training (intensity correspondent to $60 \%$ of $\mathrm{VO}_{2} \max$ ) has faster improvements of some parameters, a training with slower intensity is more tolerated and can be pursued autonomously and therefore shows long term benefits. In conclusion we see our results as a partial success considering that although the importance of exercise training in the cardiovascular disease population is recognised, only a low rate of CHF patients are currently involved in exercise rehabilitation programs [27].

This study offers a contribution in making the data in the literature more solid. In addition it presents a research and a training protocol different from all other studies. Considering also the strong prognostic value of $\mathrm{VE} / \mathrm{VCO}_{2}$ slope and its correlation with other indicators [2832], we can thus receive important information from our study, also for the prescription of a low intensity aerobic continuous exercise training to be carried out at home or in the gym for a lifetime [24].

\section{References}

1. Arena R, Myers J, Abella J, Peberdy MA, Bensimhon D, et al. (2007) Development of a ventilatory classification system in patients with heart failure. Circulation 115 : 2410-2417. [Crossref]

2. Guazzi M, Reina G, Tumminello G, Guazzi MD (2005) Exercise ventilation inefficiency and cardiovascular mortality in heart failure: the critical independent prognostic value of the arterial CO2 partial pressure. Eur Heart J 26: 472-480. [Crossref]

3. Guazzi M, Reina G, Tumminello G, Guazzi MD (2004) Improvement of alveolarcapillary membrane diffusing capacity with exercise training in chronic heart failure. $J$ Appl Physiol 97: 1866-1873. [Crossref]

4. Clarkson P, Montgomery HE, Mullen MJ, Donald AE, Powe AJ, et al. (1999) Exercise training enhances endothelial function in young men. J Am Coll Cardiol 33: 1379-1385. [Crossref]

5. Guazzi M, Raimondo R, Licenzi M, Arena R, Proserpio C, et al. (2007) Exercise oscillatory ventilation may predict sudden cardiac death in heart failure patients. $J \mathrm{Am}$ Coll Cardiol 50: 299-308. [Crossref]

6. Guazzi M, Arena R, Ascione A, Piepoli M, Guazzi MD, et al. (2007) Exercise oscillatory breathing and increased ventilation to carbon dioxide production slope in heart failure: an unfavorable combination with high prognostic value. Am Heart $J 153$ : 859-867. [Crossref]

7. Moore B, Brubaker PH, Stewart KP, Kitzman DW (2007) VE/VCO2 slope in older heart failure patients with normal versus reduced ejection fraction compared with agematched healthy controls. J Card Fail 13: 259-62. [Crossref]

8. Ingle L, Goode K, Carroll R, Sloan R, Boyes C, et al. (2007) Prognostic value of the $\mathrm{VE} / \mathrm{VCO} 2$ slope calculated from different time intervals in patients with suspected heart failure. Int J Cardiol 118: 350-355. [Crossref]

9. Tsurugaya H, Adachi H, Kurabayashi M, Ohshima S, Taniguchi K (2006) Prognostic impact of ventilatory efficiency in heart disease patients with preserved exercise tolerance. Circ J 70: 1332-1336. [Crossref]

10. Bard RL, Gillespie BW, Clarke NS, Egan TG, Nicklas JM (2006) Determining the best ventilatory efficiency measure to predict mortality in patients with heart failure. $J$ Heart Lung Transplant 25: 589-595. [Crossref]

11. Nanas SN, Nanas JN, Sakellariou DCh, Dimopoulos SK, Drakos SG, et al. (2006) VE/ $\mathrm{VCO} 2$ slope is associated with abnormal resting haemodynamics and is a predictor of long-term survival in chronic heart failure. Eur J Heart Fail 8: 420-427. [Crossref]

12. Mejhert M, Linder-Klingsell E, Edner M, Kahan T, Persson H (2002) Ventilatory variables are strong prognostic markers in elderly patients with heart failure. Heart 88: 239-243. [Crossref]

13. Guazzi M, De Vita S, Cardano P, Barlera S, Guazzi MD (2003) Normalization for peak oxygen uptake increases the prognostic power of the ventilatory response to exercise in patients with chronic heart failure. Am Heart J 146: 542-548. [Crossref]

14. Witte KK, Thackray SD, Nikitin NP, Cleland JG, Clark AL (2003) Pattern of ventilation during exercise in chronic heart failure. Heart 89: 610-614. [Crossref]

15. Wada O, Asanoi H, Miyagi K, Ishizaka S, Kameyama T, et al. (1993) Importance of abnormal lung perfusion in excessive exercise ventilation in chronic heart failure. $\mathrm{Am}$ Heart $J$ 125: 790-798. [Crossref]

16. Mohsenifar Z, Amin DK, Shah PK (1989) Regional distribution of lung perfusion and ventilation in patients with chronic congestive heart failure and its relationship to cardiopulmonary hemodinamics. Am Heart J 117: 887-891. [Crossref]

17. Daganou M, Dimopoulou I, Alivizatos PA, Tzelepis GE (1999) Pulmonary function and respiratory muscle strength in chronic heart failure: comparison between ischemic and idiopathic dilated cardiomyopathy. Heart 81: 618-620. [Crossref]

18. Hammond MD, Bauer KA, Sharp JT, Rocha RD (1990) Respiratory muscle strength in congestive heart failure. Chest 98: 1091-1094. [Crossref] 
19. Narkiewicz K, Pesek CA, van de Borne PJ, Kato M, Somers VK (1999) Enhanced sympathetic and ventilatory responses to central chemoreflex activation in heart failure. Circulation 100: 262-267. [Crossref]

20. Chua TP, Ponikowski P, Webb-Peploe K, Harrington D, Anker SD, et al. (1997) Clinical characteristics of chronic heart failure patients with an augmented peripheral chemoreflex. Eur Heart $J$ 18: 480-486. [Crossref]

21. Chua TP, Clark AL, Amadi AA, Coats AJ (1996) Relation between chemosensitivity and the ventilatoty response to exercise in chronic heart failure. $J$ Am Coll Cardiol 27: 650-657. [Crossref]

22. Sun XG, Hansen JE, Garatachea N, Storer TW, Wasserman K (2002) Ventilatory efficiency during exercise in healthy subjects. Am J Respir Crit Care Med 166: 14431448. [Crossref]

23. Beaver WL, Wasserman K, Whipp BJ (1986) A new method for detecting anaerobic threshold by gas exchange. $J$ Appl Physiol 60: 2020-2027. [Crossref]

24. Sarto P, Balducci E, Balconi G, Fiordaliso F, Merlo L, et al. (2007) Effects of exercise training on endothelial progenitor cells in patients with chronic heart failure. $J$ Card Fail 13: 701-708. [Crossref]

25. Xie B, Yan X, Cai X, Li J (2017) Effects of High-Intensity Interval Training on Aerobic Capacity in Cardiac Patients: A Systematic Review with Meta-Analysis. Biomed Res Int 2017: 5420840. [Crossref]
26. Berra K, Houston Miller N, Fair JM (2006) Cardiovascular disease prevention and disease management: a critical role for nursing. J Cardiopulm Rehabil 26: 197-206.

27. Conti AA, Macchi C, Molino Lova R, Conti A, Gensini GF (2007) Relationship between physical activity and cardiovascular disease: Selected historical highlights. $J$ Sports Med Phys Fitness 47: 84-90. [Crossref]

28. Pereira-da-Silva T, M Soares R, Papoila AL, Pinto I, Feliciano J, et al. (2018) Optimizing risk stratification in heart failure and the selection of candidates for heart transplantation. Rev Port Cardiol S0870-2551: 30064-1. [Crossref]

29. Popovic D, Arena R, Guazzi M (2018) A flattening oxygen consumption trajectory phenotypes disease severity and poor prognosis in patients with heart failure with reduced, mid-range, and preserved ejection fraction: $\mathrm{VO} 2$ trajectory flattening in heart failure. Eur J Heart Fail [Crossref]

30. Vainshelboim B, Amin A, Christle JW, Hebbal S, Ashley EA, et al. (2017) A method for determining exercise oscillatory ventilation in heart failure: Prognostic value and practical implications. Int J Cardiol 15: 287-291. [Crossref]

31. Mezzani A, Giordano A, Komici K, Corrà U (2017) Different Determinants of Ventilatory Inefficiency at Different Stages of Reduced Ejection Fraction Chronic Heart Failure Natural History. J Am Heart Assoc: Cardiovascular and Cerebrovascular Disease 6: e005278. [Crossref]

32. Mífková L, Várnay F, Homolka P, Dobšák P (2017) An assessment of VO2 kinetics in the recovery phase of cardiopulmonary exercise test in patients with heart diseaseimportance and classification. Vnitr Lek 63: 107-113. [Crossref]

Copyright: @2018 Scarpa S. This is an open-access article distributed under the terms of the Creative Commons Attribution License, which permits unrestricted use, distribution, and reproduction in any medium, provided the original author and source are credited. 